I.I. Mechnikov National University of Odesa

(2, Dvoryans'ka Str., Odesa 65026, Ukraine; e-mail: yevelic@gmail.com)

\title{
SIMULATION OF THE INTERACTION PACS 34.20.Gj, 51.30.+i POTENTIAL BETWEEN WATER MOLECULES
}

\begin{abstract}
The structure and the explicit form of the interaction potential between molecules in water vapor have been studied. The main contribution to this potential is supposed to be made by repulsive, dispersion, and electrostatic forces. The irreducible contribution caused by the overlapping of the electron shells of water molecules, which is usually associated with hydrogen bonds, is supposed to be small and neglected. Interaction potentials, in which the molecular repulsion is described by either a "soft" power-law potential or a hard-core one, have been constructed. In both cases, a multipole series expansion up to the dipole-octupole term is used for the electrostatic interaction between molecules. The dispersion interaction is approximated by the standard London formula. The multipole moments are taken to be equal to their experimental values or close to their values obtained from quantum chemical calculations. The model parameters for the repulsive and dispersion potentials are selected to correctly reproduce the parameters of an isolated dimer and the temperature dependence of the second virial coefficient. The obtained potentials are used to construct the average potentials of interaction between the molecules, which govern the thermodynamic, kinetic, and electrophysical properties of water vapor. A characteristic feature of the repulsive potential is the value of power exponent: $n=28$. The proposed potentials differ substantially from the well-known ones, such as $S P C, S P C / E$, TIPS, and other potentials.
\end{abstract}

Keywords: water vapor, molecular interaction potential.

\section{Introduction}

The development of a consistent statistical theory for the properties of water, as well as aqueous alcohol solutions, in the liquid and vapor states is associated with the problem to adequately describe the interaction potentials between molecules. The difficulty of the situation consists in that water molecules and molecules of alcohols belonging to the methanol series are multiatomic. The potentials of interaction between them depend on their molecular orientation, the distance between them, and the presence of hydrogen bonds (as such, contributions to the molecular interaction associated with the overlapping of electron shells belonging to different molecules are understood).

There are a number of initial potentials describing the molecular interaction in water and methanol. For example, these are the SPC [1], TIP3P [2], and TIP5P [3] potentials for water, the OPLS model [4] for methanol, and others. However, the parameters

(C) M.V. TIMOFEEV, 2016

ISSN 2071-0194. Ukr. J. Phys. 2016. Vol. 61, No. 10 in those potentials were selected to reproduce that or another property of water or methanol in the liquid state. In particular, the SPC potential includes contributions from the repulsive, dispersion, and electrostatic interactions between effective charges. The dispersion interaction between water molecules is evaluated in the London approximation (see work [5]). The parameters of the repulsive potential and the magnitudes of effective charges are determined according to the criterion that the evaporation heat and the pressure of water at $T=298 \mathrm{~K}$ should be correctly reproduced [1].

A direct application of those potentials to describe the properties of water in the vapor phase is not quite correct. As is shown below, they unsatisfactorily reproduce the dipole and quadrupole moments of isolated water molecules, as well as the temperature dependence of the second virial coefficient of water.

We should take into account that water and methanol molecules are in the state of permanent thermally induced rotation. As a result, the potentials of molecular interaction become averaged over their an- 
gular variables [6]. Really, the characteristic rotation time for the molecules equals $\tau_{r} \sim \frac{2 \pi}{\omega_{r}} \sim 2 \pi\left(\frac{I}{k_{\mathrm{B}} T}\right)^{1 / 2}$, where $I$ is the moment of inertia of a molecule. It turns out substantially shorter than the mean free time $\tau_{f} \sim \frac{1}{\sqrt{2} \pi d^{2} n \bar{v}}$, where $\sigma$ is the effective diameter of the molecule, $n$ the molecular concentration, and $v_{T}=\sqrt{\frac{3 k_{\mathrm{B}} T}{m}}$ the average thermal velocity of molecular motion. For water, the inequality $\tau_{r} \ll \tau_{f}$ is obeyed up to concentrations $n \ll n_{*}$, where $n_{*}^{(w)} \sim 0.7 \times 10^{22} \mathrm{~cm}^{-3}$ is close to the concentration of water molecules near the ternary point $\left(n_{\mathrm{tr}}^{(w)} \sim 3.3 \times 10^{22} \mathrm{~cm}^{-3}\right)$. Thus, the limiting value of concentration, $n_{*}$, tends to the corresponding value at the ternary point, which testifies that the relation $\tau_{r} \ll \tau_{f}$ is practically correct within the whole interval of vapor state existence from the ternary point to the critical one. Note that, in the case of liquids, the characteristic time of molecular rotation is much shorter than the characteristic time needed for the configuration formed by the nearest neighbors to change.

Hence, the thermodynamic properties of liquid and vapor water within a wide temperature interval are governed by radially symmetric pair potentials. Effects associated with orientational correlations [7] manifest themselves only at low enough temperatures.

The potential of molecular interaction is so averaged over the angular variables that the configuration integral should remain invariable in the pairinteraction approximation:

$\oint_{\Omega_{1}} \frac{d \Omega_{1}}{8 \pi^{2}} \oint_{\Omega_{2}} \frac{d \Omega_{2}}{8 \pi^{2}} \exp \left(-\beta \Phi\left(r, \Omega_{1}, \Omega_{2}\right)\right)=$

$=\exp \left(-\beta U^{(a)}(r)\right)$

where $\Omega$ is a set of angular variables describing the axis orientation in the molecular coordinate system, $r$ the distance between the centers of mass of the molecules, and $\beta=\frac{1}{k_{\mathrm{B}} T}$.

The standard averaged value of the interaction potential, $U_{a}$, is defined by the expression

$U_{a}(r)=\frac{\int \exp \left(-\beta \Phi\left(r, \Omega_{1}, \Omega_{2}\right)\right) \Phi\left(r, \Omega_{1}, \Omega_{2}\right) d \Omega_{1} d \Omega_{2}}{\int \exp \left(-\beta \Phi\left(r, \Omega_{1}, \Omega_{2}\right)\right) d \Omega_{1} d \Omega_{2}}$,

where $\Phi\left(r, \Omega_{1}, \Omega_{2}\right)$ is the initial potential. The averaged potentials $U_{a}(r)$ and $U^{(a)}(r)$ are substantially different from each other. However, if the inequality $|-\beta \Phi| \ll 1$ is satisfied, they are connected by the simple formula $U^{(a)} \approx \frac{1}{2} U_{a}$.

The aim of this work is to construct the initial potential of molecular interaction in the vapor phase of water. Further, this potential is applied to construct the averaged interaction potential and to reproduce the temperature dependence of the second virial coefficient. In the paper, the dimensionless quantities of the type $\tilde{A}=\frac{A}{\mu_{A}}$, where $\mu_{A}$ is a characteristic value of the quantity $A$, are used. In particular, the characteristic distance scale $\mu_{r}$ is determined as the distance between the oxygens in the ground state of a water dimer: $\mu_{r}=r_{O O}, r_{O O}=2.98 \AA$ [8]. The quantity $\mu_{\varepsilon}=k_{\mathrm{B}} T_{\mathrm{tr}}$, where $k_{\mathrm{B}}$ is the Boltzmann constant and $T_{\mathrm{tr}}$ the temperature at the ternary point of water, serves as the energy scale, and the temperature is measured in the units $\mu_{T}=T_{\mathrm{tr}}$. The quantity $\mu_{B}=r_{O O}^{3}$ is a measurement unit for the second virial coefficient.

\section{Initial Interaction Potential between Water Molecules}

The potential of interaction between water molecules in the vapor phase, $\Phi$, has the following structure:

$\Phi=\Phi_{R}+\Phi_{D}+\Phi_{E}+\Phi_{H}$.

Here, $\Phi_{R}$ is the repulsive potential, $\Phi_{D}$ the component corresponding to the dispersion interaction, $\Phi_{E}$ the potential of electrostatic interaction between the molecules, and $\Phi_{H}$ the contribution given by hydrogen bonds. In work [9], it was shown that the contribution of hydrogen bonds is small enough, so that it is neglected below.

The electrostatic interaction between water molecules is described by means of a multipole series expansion.

\subsection{Repulsive and dispersion interactions}

The dispersion interaction is simulated by the expression

$\Phi_{D}(r)=-\varepsilon_{D} \frac{\sigma^{6}}{r^{6}}$,

where $\varepsilon_{D}$ is the energy of dispersion interaction at the distance $\sigma$. The value of quantity $A_{D}=\varepsilon_{D} \sigma^{6}$, similarly to what was done in the SPC potential, is evaluated with the help of the London formula and equals $\tilde{A}_{D}=1.646$ [1].

ISSN 2071-0194. Ukr. J. Phys. 2016. Vol. 61, No. 10 
The potential of molecular repulsion is simulated by either the repulsive potential of the hard-core type,

$\Phi_{R}(r)= \begin{cases}\infty, & r<\sigma \\ 0, & \sigma \leq r\end{cases}$

or the power-law potential

$\Phi_{R}(r)=\varepsilon_{R} \frac{\sigma^{n}}{r^{n}}$.

The power exponent $n$ and the value of $\varepsilon_{R}$ are chosen to satisfy the following conditions: 1) the reproduction of the temperature dependence for the second virial coefficient and 2) the reproduction of equilibrium parameters for a water dimer. The quantity $r$ means the distance between the centers of oxygen atoms in the water molecules. The notation $A_{R}(n)$ will be used for the product $\varepsilon_{R}(n) \sigma^{n}$.

The parameters of some known potentials describing the repulsive and dispersion interactions between water molecules are quoted in Table 1.

\subsection{Simulation of the electrostatic interaction by a multipole series expansion}

In the multipole series expansion of the potential of electrostatic interaction between water molecules, only the contributions up to the dipole-octupole term $\Phi_{D O}$, inclusive, are taken into consideration:

$\Phi_{E}=\Phi_{D D}+\Phi_{D Q}+\Phi_{Q Q}+\Phi_{D O}$.

The explicit expressions for the terms in Eq. (6) are

$$
\begin{aligned}
& \Phi_{D D}=-\frac{1}{\tilde{r}^{3}}\left[3\left(n_{\alpha} d_{\alpha}^{(1)}\right)\left(n_{\beta} d_{\beta}^{(2)}\right)-d_{\alpha}^{(1)} d_{\alpha}^{(2)}\right], \\
& \Phi_{D Q}=\frac{1}{r^{4}}\left[5 \left[\left(n_{\alpha} d_{\alpha}^{(1)}\right)\left(n_{\beta} n_{\gamma} Q_{\beta \gamma}^{(2)}\right)-\right.\right. \\
& \left.-\left(n_{\gamma} d_{\gamma}^{(2)}\right)\left(n_{\alpha} n_{\beta} Q_{\alpha \beta}^{(1)}\right)\right]+ \\
& \left.+2\left(d_{\alpha}^{(2)} Q_{\alpha \beta}^{(1)} n_{\beta}-d_{\alpha}^{(1)} Q_{\alpha \gamma}^{(2)} n_{\gamma}\right)\right], \\
& \Phi_{Q Q}=\frac{1}{3 r^{5}}\left[35\left(n_{\alpha} Q_{\alpha \beta}^{(1)} n_{\beta}\right)\left(n_{\gamma} Q_{\gamma \lambda}^{(2)} n_{\lambda}\right)-\right. \\
& \left.-20 n_{\alpha} Q_{\alpha \beta}^{(1)} Q_{\beta \lambda}^{(2)} n_{\lambda}+2 Q_{\alpha \beta}^{(1)} Q_{\alpha \beta}^{(2)}\right], \\
& \Phi_{D O}=-\frac{1}{r^{5}}\left[7 \left[\left(n_{\alpha} d_{\alpha}^{(1)}\right)\left(n_{\beta} n_{\gamma} n_{\lambda} O_{\beta \gamma \lambda}^{(2)}\right)+\right.\right.
\end{aligned}
$$

ISSN 2071-0194. Ukr. J. Phys. 2016. Vol. 61, No. 10

$$
\begin{aligned}
& \left.+\left(n_{\lambda} d_{\lambda}^{(2)}\right)\left(n_{\alpha} n_{\beta} n_{\gamma} O_{\alpha \beta \gamma}^{(1)}\right)\right]- \\
& \left.-3\left(n_{\beta} n_{\gamma} O_{\beta \gamma \alpha}^{(2)} d_{\alpha}^{(1)}+n_{\beta} n_{\gamma} O_{\beta \gamma \alpha}^{(1)} d_{\alpha}^{(2)}\right)\right] .
\end{aligned}
$$

Here, the summation over repeated subscripts is implied; the subscripts $d, Q$, and $O$ designate the dipole, quadrupole, and octupole moments, respectively; $\mathbf{n}$ is a unit vector directed along the axis that passes through the centers of mass of two water molecules; and $r$ the distance between the centers of mass of interacting molecules.

\subsection{Multipole moments}

Unfortunately, the multipole moments of model charges that enter the SPC, TIPS, and so on potentials cannot be used to describe the electrostatic interaction between water molecules in gases. It is so, because the multipole moments that correspond to the arrangement of effective charges in those potentials differ considerably from the moments obtained experimentally $[10,11]$ or calculated using the methods of quantum chemistry [12] (see Table 2). For instance, the dipole moment of a water molecule in the gas phase equals $d=1.855 \mathrm{D}$ [10], whereas the effective charges of the SPC potential [1] bring about the value $d=2.35 \mathrm{D}$. For this reason, the reproduction of the temperature dependence for the second virial coefficient turns out unsatisfactory in comparison with experimental values $[13,14]$.

The multipole moments of a water molecule, which are quoted in Tables 2 and 3, were calculated in the

Table 1. $\tilde{A}_{\boldsymbol{R}}(\boldsymbol{n})$ - and $\tilde{A}_{D^{-v a l u e s}}$

for some model potentials of water at $n=12$

\begin{tabular}{|l|l|l|l|l|}
\hline & TIPS & SPC & TIP4P & TIP5P \\
\hline$\tilde{A}_{R}$ & 2.189 & 2.376 & 2.265 & 2.055 \\
$\tilde{A}_{D}$ & 1.388 & 1.653 & 1.613 & 1.56 \\
\hline
\end{tabular}

Table 2. Components of the quadrupole moment of an isolated water molecule in the gas phase

\begin{tabular}{|l|c|c|c|}
\hline & $Q_{x x}, D \cdot A$ & $Q_{y y}, D \cdot A$ & $Q_{z z}, D \cdot A$ \\
\hline Zeeman eff. [11] & 2.63 & -2.50 & -0.13 \\
Quant. chem. [12] & 2.61 & -2.48 & -0.13 \\
SPC [1] & 2.11 & -1.82 & -0.29 \\
\hline
\end{tabular}




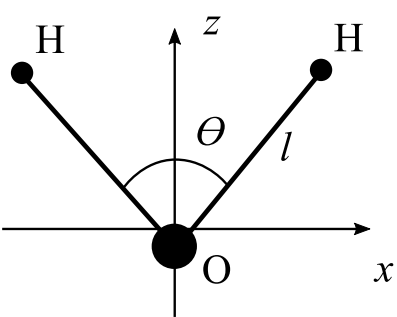

Fig. 1. Molecular coordinate system for a water molecule

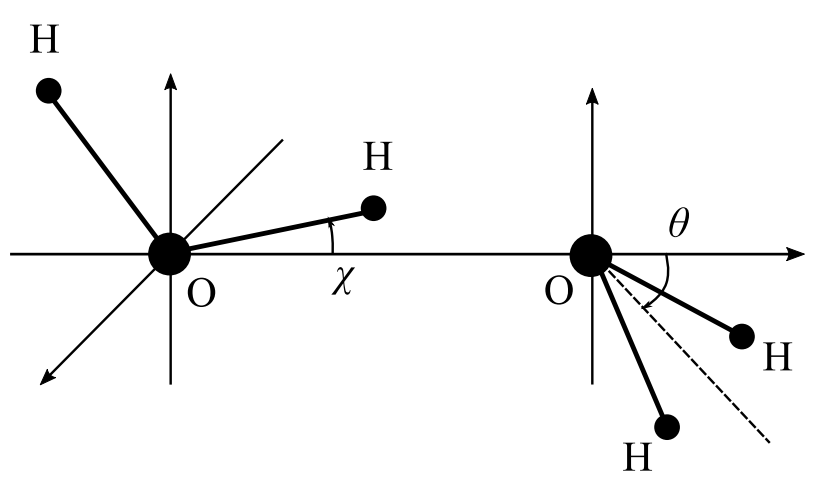

Fig. 2. Equilibrium configuration of a water dimer

molecular coordinate system depicted in Fig. 1. Note that the origin of this coordinate system is located at the center of mass of a water molecule, which is shifted by about $0.06 \AA$ with respect to the center of the oxygen atom along the bisectrix, i.e. along the axis $z$. The geometric parameters of the water molecule are $\theta=104.5^{\circ}$ and $l=0.957 \AA$ [15].

Table 3. Components of the octupole moment of an isolated water molecule in the gas phase

\begin{tabular}{|c|c|c|c|}
\hline & $O_{z x x}, D \cdot A^{2}$ & $O_{z y y}, D \cdot A^{2}$ & $O_{z z z}, D \cdot A^{2}$ \\
\hline Quant. chem. [12] & -2.33 & 0.97 & 1.36 \\
\hline
\end{tabular}

Table 4. $\tilde{\boldsymbol{A}}_{\boldsymbol{R}}(\boldsymbol{n})$-values in potential

(5) and dimer characteristics at various values of exponent $n$

\begin{tabular}{|l|c|c|c|c|}
\hline \multicolumn{1}{|c|}{$n$} & 12 & 18 & 24 & 28 \\
\hline$\tilde{A}_{R}(n)$ & 2.323 & 1.756 & 1.558 & 1.506 \\
$\tilde{r}_{O O}$ & 0.931 & 0.97 & 0.987 & 0.995 \\
$\theta,^{\circ}$ & 35.2 & 34.7 & 34.6 & 34.5 \\
$\chi,^{\circ}$ & 2.39 & 2.84 & 3.03 & 3.1 \\
\hline
\end{tabular}

One should pay attention to that the tabulated values for the components of multipole moments are given, as a rule, in the center-of-mass coordinate system. For the calculation of the parameters of a water dimer, a coordinate system with the origin at the center of the oxygen atom turns out to be more convenient. The corresponding recalculation of the components of multipole moments changes the dimer parameters by a few percent only.

\section{Description of a Water \\ Dimer and the Second Virial Coefficient of Water Vapor}

As follows from our consideration, the parameters $A_{R}, A_{D}$, and $n$ remained uncertain. For their determination, the dimer energy in the ground state, the dipole moment of a dimer, and the temperature dependence of the second virial coefficient were used. The ground state of a dimer could be characterized by the distance between the oxygen atoms. However, a very smooth shape of the potential surface near its minimum forced us to choose the ground-state energy for this purpose.

The relative arrangement of water molecules, which corresponds to the dimer ground state, is depicted in Fig. 2. The value of $A_{R}$ at various $n$ are calculated as the roots of the equation $E_{d}\left(A_{R}\right)=E_{d}^{(\exp )}$, where $\tilde{E}_{d}^{(\exp )}=9.96[16]$, and

$\min \left[\Phi\left(A_{R}, r, \theta, \chi\right)\right]=\Phi\left(A_{R}, r_{\min }, \theta_{\min }, \chi_{\min }\right)=$ $=E_{d}\left(A_{R}\right)$.

The values of the coefficient $A_{R}$ found at various values of the exponent $n$ and the major parameters of the dimer are quoted in Table 4 . The values of the angle $\chi$ were determined by reproducing the dipole moment of a dimer [17] and satisfying the condition of a univocal interrelation between $\theta$ and $\chi$. The best agreement of the found distance between the oxygen atoms in water molecules with the experimental value [8] was obtained for the exponent value $n=28$. This value for the exponent in the repulsive potential is not at all extraordinary. In work [18], it was shown that the value $n=28$ was observed even for argon. It is typical even of the repulsive potential for some molecular liquids, which were considered in work [19].

The value of $\sigma$ for potential (4) was sought together with the value of $A_{D}$ for potential (3). Knowing $\sigma$, the value of $A_{D}$ was determined from the condition

ISSN 2071-0194. Ukr. J. Phys. 2016. Vol. 61, No. 10 
$E_{d}\left(A_{D}, \sigma\right)=E_{d}^{(\exp )}$. Then $\sigma$ was determined by fitting the temperature dependence of the experimental values of second virial coefficient $[13,14]$, by using the least-squares method. The following values were obtained: $\tilde{\sigma}=1.077, \tilde{A}_{D}=4.02, \theta=33.7^{\circ}$, and $\chi=3.9^{\circ}$.

\section{Averaged Potential of Interaction between Water Molecules}

Now, let us construct the averaged potential of molecular interaction, which includes the multipole series expansion (6), the dispersion interaction in form (3), and power-law repulsive potential (5) with $n=28$. The result is shown in Fig. 3. The symbols represent the values of averaged potential $U_{a}(r)$ at $T=308 \mathrm{~K}$, and the solid curve displays the result of their approximation with the use of the potential

$U(r)=4 \varepsilon(n)\left[\left(\frac{\sigma(n)}{r}\right)^{n}-\left(\frac{\sigma(n)}{r}\right)^{6}\right]$

with $n=28$. The $\sigma$ - and $\varepsilon$-values in expression (7), which were found at various temperatures by the least-squares method, are shown in Table 5.

It should be noted that the parameters $\sigma$ and $\varepsilon$ in the effective interaction potential between water molecules are temperature-dependent. This fact demands to be careful, when working with such potentials, because all standard relations in statistical mechanics correspond to potentials that do not depend on the concentration and the temperature. An earlier consideration of this circumstance can be found in work [20]. We only add here that the location of the minimum in the averaged potential grows from 1.0066 to 1.0104 in dimensionless units within the temperature interval spanned in Table 5. This fact is equivalent to the statement that the electron shells of water molecules practically do not overlap. Really, the maximum value of the parameter of electron shell overlapping

$\Delta=1-\frac{1}{\tilde{r}_{O O}} \leq 0.01$

does not exceed $1 \%$, which completely justifies the neglect of the contribution from "hydrogen bonds".

\section{Temperature Dependence of the Second Virial Coefficient}

In the general case, the second virial coefficient depends on the initial potential according to the for-

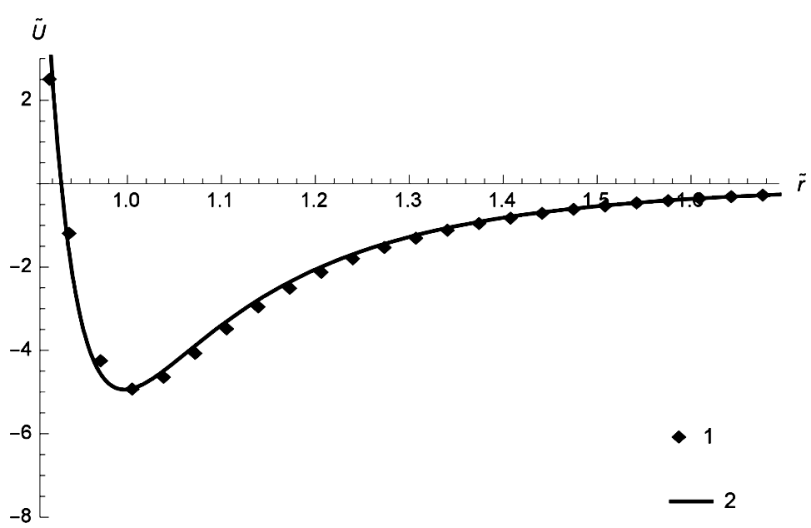

Fig. 3. Averaged interaction potential between water molecules: numerical values (1), approximation (2)

mula $[21,22]$

$B(T)=\frac{1}{2 V \Omega_{0}^{2}} \int_{\Gamma}\left(1-\exp \left[-\beta \Phi\left(r, \Omega_{1}, \Omega_{2}\right)\right]\right) d \Gamma_{1} d \Gamma_{2}$,

where $d \Gamma_{i}=d \mathbf{r}_{i} d \Omega_{i}, \mathbf{r}$ is the radius vector of the $i$-th molecule, and $\Omega_{0}$ a phase volume corresponding to a certain choice of angular variables.

It is easy to see that, after integration over the angular variables, the expression for the second virial coefficient is reduced to the standard form [21], which now includes the averaged potential:

$B(T)=2 \pi \int_{r}\left(1-e^{-\beta U_{a}(r)}\right) r^{2} d r$.

The behavior of the second virial coefficient $B(T)-$ it is governed by the averaged potential $U_{a}(r)$, which is described by formula $(7)$ - calculated at various $n$ is depicted in Fig. 4. One can see that the best agreement with experimental data is obtained at $n=$ $=18,24$, and 28 (practically to the same accuracy), which are far from the conventional value $n=12$.

Table 5. $\tilde{\sigma}$ - and $\tilde{\varepsilon}$-values in potential (7)

at $n=28$, the locations $\tilde{r}_{O O}$ and the depths

$\tilde{U}_{\min }^{(a)}$ of averaged potentials at various temperatures

\begin{tabular}{|c|c|c|l|l|}
\hline$T, \mathrm{~K}$ & $\tilde{\sigma}$ & $\tilde{\varepsilon}$ & $\tilde{r}_{O O}$ & $\tilde{U}_{\min }^{(a)}$ \\
\hline 308 & 0.929 & 2.392 & 1.0066 & -4.95 \\
338 & 0.931 & 2.287 & 1.0071 & -4.74 \\
423 & 0.936 & 2.031 & 1.009 & -4.24 \\
473 & 0.938 & 1.909 & 1.0104 & -3.99 \\
\hline
\end{tabular}




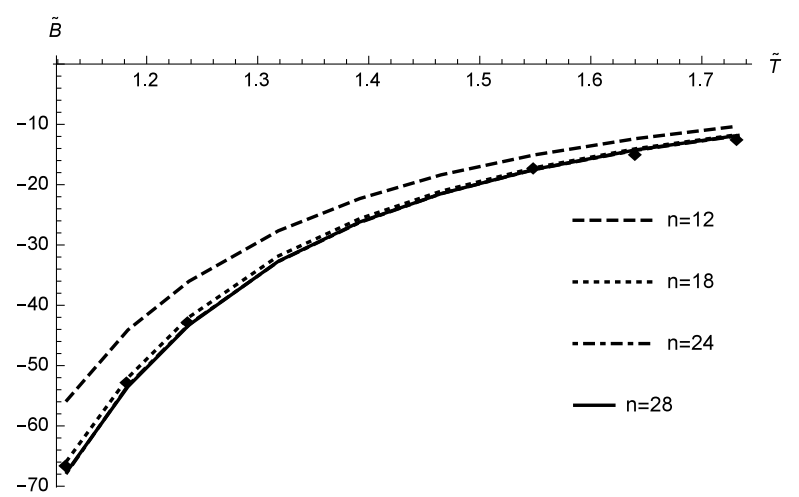

Fig. 4. Second virial coefficient for various values of exponent $n$ in the repulsive potential (5). Symbols correspond to experimental values $[13,14]$

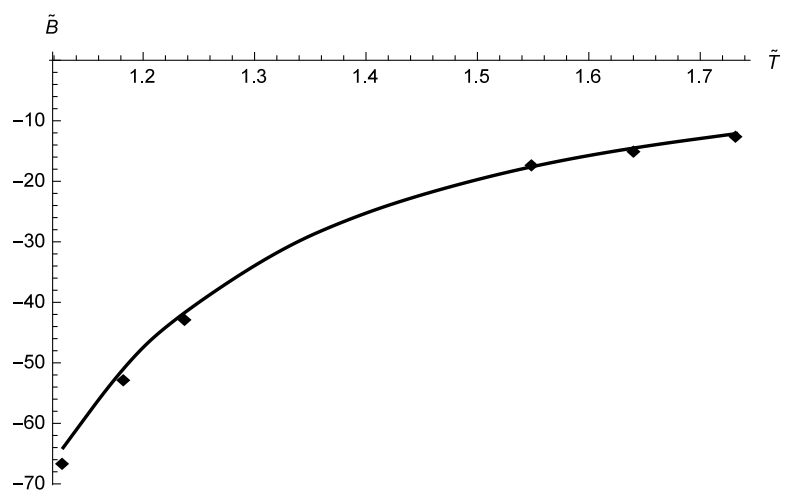

Fig. 5. Second virial coefficient calculated for water vapor using the hard-core potential (4) for the repulsion

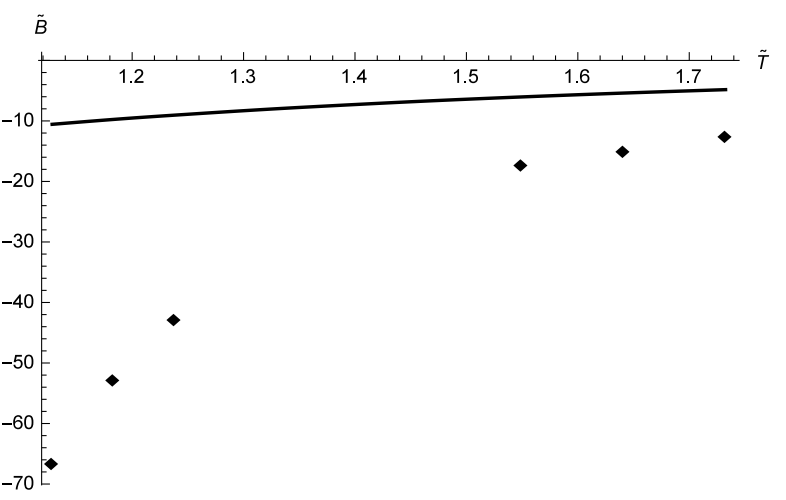

Fig. 6. Second virial coefficient of water vapor calculated in the approximation $|\beta U| \ll 1$ : symbols $[13,14]$, curve (Eq. (8))

The temperature dependence of the second virial coefficient for water vapor calculated with the Sutherland potential (4) with $\tilde{\sigma}=1.077$ and $\tilde{A}_{D}=4.02$ is shown in Fig. 5.
The second virial coefficient is often determined, by using the simplified expression [21]

$$
B(T)=2 \pi \frac{\sigma^{3}}{3}-\frac{2 \pi}{k_{\mathrm{B}} T} \int_{\sigma<r}|U(r)| r^{2} d r .
$$

A comparison of $B(T)$-values obtained in this case with their experimental counterparts is demonstrated in Fig. 6. While calculating $B(T)$, we used the averaged potential constructed with the inclusion of the repulsive potential (4) with the parameters indicated above. From whence, it follows that the application of the simplified expression (8) turns out absolutely unsatisfactory.

\section{Discussion \\ of the Results Obtained}

For the description of the properties of water vapor, we need a rather detailed information concerning the potential of molecular interaction. It is so because of the formation of dimers, trimers, and higher-order multimers. These components of water vapor make crucial contributions to such vapor properties as the dielectric permittivity and the heat capacity. Therefore, the requirements to the accuracy of a molecular interaction reproduction are much more rigorous in comparison with other low-molecular systems consisting, for example, of nitrogen or benzene molecules. Unfortunately, as was marked in Introduction, the interaction potentials between water molecules that are used today are unsatisfactory.

Our approach to the construction of a satisfactory initial potential of molecular interaction is based on the following assumptions. (i) This potential is a sum of the repulsive, dispersion, and electrostatic components. (ii) The electrostatic component is simulated by a multipole series expansion to the dipole-octupole term inclusive. (iii) The dispersion interaction is accepted to be standard. (iv) The repulsion potential is simulated by either a power-law expression or the expression obtained in the hard-core model. The interaction that emerges owing to a weak overlapping of electron shells in water molecules and has the meaning of an irreducible hydrogen bond [9] can be neglected.

In effect, the size of a water molecule enters only the repulsive potential component. For its determination and for the determination of the repulsion constant, we analyzed (a) the properties of an isolated dimer

ISSN 2071-0194. Ukr. J. Phys. 2016. Vol. 61, No. 10 
and (b) the temperature dependence of the second virial coefficient. In so doing, we confined the consideration to a temperature interval, in which the dimerization does not take place [23].

Moreover, the simplest thermodynamic properties of water vapor, such as the equation of state or the coexistence curve, are governed by the averaged potentials of molecular interaction. Actually, the averaging of the potentials is a self-averaging, which is connected with molecular rotation.

In this work, it was shown that the averaged interaction potential has a structure that reminds the Lennard-Jones potential. However, the exponent in the repulsive component equals $n=28$, and the temperature dependences of the second virial coefficient at $n=18,24$, and 28 are almost identical. As a rule, this exponent is taken to equal 12 , as was done in works [1-3]. On the other hand, in works [18, 19], it was shown that even in the case of simple liquids of the argon type, the exponent value differs from 12 .

The values of the parameters $\sigma$ and $\varepsilon$ in potential (7), as well as the corresponding depths of its well, $\tilde{U}_{\text {min }}^{(a)}$, obtained for various values of the exponent $n$ are presented in Table 6.

The approximation quality for the averaged interaction potential between water molecules $U_{a}$ by the standard Lennard-Jones potential at $\tilde{\sigma}=0.877$ and $\tilde{\varepsilon}=3.547$ is illustrated in Fig. 7. The averaged potential $U_{a}$ was constructed with the use of the power-law repulsive potential (5) with $n=28$. The approximation was obtained under the condition of asymptotic convergence of the Lennard-Jones potential with the potential $U_{a}$ at relatively large distances (more than $4 \AA$ ). At relatively short distances, those potentials are different: the depth of the Lennard-Jones potential turns out to be underestimated by a factor of about 1.5 , and the potential wall is shifted by $0.15 \AA$ to the left, but the positions of minima practically coincide. Hence, the Lennard-Jones potential does not

Table 6. Dependences of the $\tilde{\sigma}$ - and $\tilde{\varepsilon}$-values and the depths $\tilde{U}_{\min }^{(a)}$ of the averaged potential (7) on the exponent $n$ at $T=308 \mathrm{~K}$

\begin{tabular}{|c|c|c|c|c|}
\hline$n$ & 12 & 18 & 24 & 28 \\
\hline$\tilde{\sigma}$ & 0.849 & 0.896 & 0.919 & 0.929 \\
\hline$\tilde{\varepsilon}$ & 4.36 & 3.072 & 2.593 & 2.392 \\
\hline$\tilde{U}_{\min }^{(a)}$ & -4.36 & -4.72 & -4.89 & -4.95 \\
\hline
\end{tabular}

ISSN 2071-0194. Ukr. J. Phys. 2016. Vol. 61, No. 10

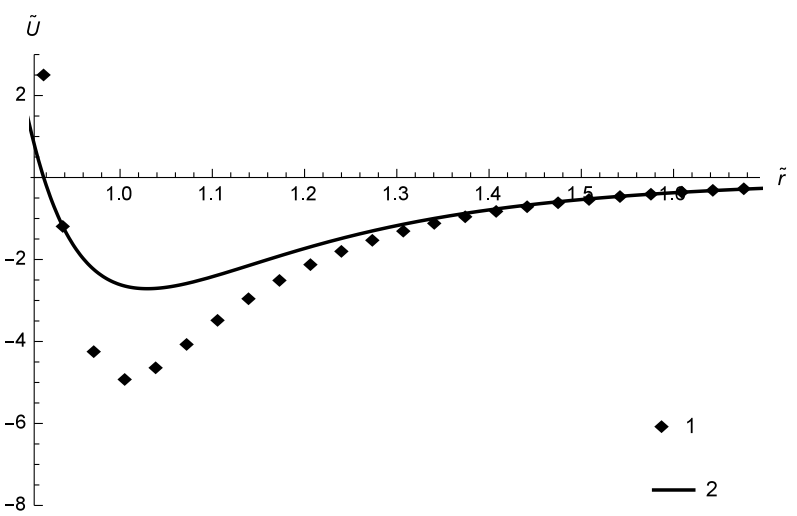

Fig. 7. Averaged potential $U_{a}$ at $n=28(1)$ and its approximation by the Lennard-Jones potential (2)

provide a satisfactory approximation for the averaged potential $U_{a}$, if the exponent $n$ in the repulsive potential equals 28 .

Note that the electrostatic component of the molecular interaction was simulated in work [24] in the same way. However, the cited authors used the values of multipole moments that corresponded to the model SPC/E and TIP5P potentials. As a consequence, the properties of a dimer and the second virial coefficient were reproduced incorrectly.

The author expresses his gratitude to Professor M.P. Malomuzh for a detailed discussion of the results of this work and good advices, as well as to the senior research assistant V.Yu. Bardika for consultations on the repulsive potential behavior.

1. H.J.C. Berendsen, J.P.M. Postma, W.F. van Gunsteren, and J. Hermans, in Intermolecular Forces, edited by B. Pullman (Reidel, Dordrecht, 1981), p. 331 [DOI: 10.1007/978-94-015-7658-1_21].

2. W.L. Jorgensen, J. Chandrasekhar, J.D. Madura, R.W. Impey, and M.L. Klein, Comparison of simple potential functions for simulating liquid water, J. Chem. Phys. 79, 926 (1983) [DOI: 10.1063/1.445869].

3. M.W. Mahoney and W.L. Jorgensen, A five-site model for liquid water and the reproduction of the density anomaly by rigid, nonpolarizable potential functions, J. Chem. Phys. 112, 8910 (2000) [DOI: 10.1063/1.481505].

4. W.L. Jorgensen, Optimized intermolecular potential functions for liquid alcohols, J. Phys. Chem. 90, 1276 (1986) [DOI: 10.1021/j100398a015].

5. I.G. Kaplan, Theory of Molecular Interactions (Elsevier, Amsterdam, 1986).

6. S.V. Lishchuk, N.P. Malomuzh, and P.V. Makhlaichuk, Why thermodynamic properties of normal and heavy wa- 
ter are similar to those of argon-like liquids? Phys. Lett. A 374, 2084 (2010) [DOI: 10.1016/j.physleta.2010.02.070].

7. S.V. Lishchuk, N.P. Malomuzh, and P.V. Makhlaichuk, Contribution of H-bond vibrations to heat capacity of water, Phys. Lett. A 375, 2656 (2011) [DOI: 10.1016/j.physleta.2011.05.049].

8. J. Odutola and T.R. Dyke, Partially deuterated water dimers: Microwave spectra and structure, J. Chem. Phys. 72, 5062 (1980) [DOI: 10.1063/1.439795].

9. P.V. Makhlaichuk, M.P. Malomuzh, and I.V. Zhyganiuk, Nature of hydrogen bond in water, Ukr. J. Phys. 57, 113 (2012).

10. S.L. Shostak, W.L. Ebenstein, and J.S. Muenter, The dipole moment of water. I. Dipole moments and hyperfine properties of $\mathrm{H}_{2} \mathrm{O}$ and $\mathrm{HDO}$ in the ground and excited vibrational states, J. Chem. Phys. 94, 5875 (1991) [DOI: 10.1063/1.460471].

11. J. Verhoeven and A. Dymanus, Magnetic properties and molecular quadrupole tensor of the water molecule by beam-maser Zeeman spectroscopy, J. Chem. Phys. 52, 3222 (1970) [DOI: 10.1063/1.1673462].

12. E.R. Batista, S.S. Xantheas, and H. Jonsson, Molecular multipole moments of water molecules in ice Ih, J. Chem. Phys. 109, 4546 (1998) [DOI: 10.1063/1.477058].

13. N.S. Osborne, H.F. Stimson, and D.C. Ginnings, Calorimetric determination of the thermodynamic properties of saturated water in both the liquid and gaseous states from 100 to $374{ }^{\circ} \mathrm{C}$, J. Res. Natl. Bur. Stand. 18, 389 (1937) [DOI: $10.6028 /$ jres.018.020].

14. N.S. Osborne, H.F. Stimson, and D.C. Ginnings, Thermal properties of saturated water and steam, J. Res. Natl. Bur. Stand. 23, 197 (1939) [DOI: 10.6028/jres.023.009].

15. J.B. Hasted, in Water: A Comprehensive Treatise, edit. by F. Franks (Plenum Press, New York, 1972), Vol. 1, p. 255 [ISBN 9780306371813].

16. Yu.M. Kessler, V.E. Petrenko, A.K. Lyashchenko et al., Water: Structure, State, Solvation (Nauka, Moscow, 2003) (in Russian).

17. N.P. Malomuzh, V.N. Makhlaichuk, and S.V. Khrapatyi, Water dimer dipole moment, Russ. J. Phys. Chem. A 88, 1431 (2014) [DOI: 10.1134/S0036024414080172].

18. V.Yu. Bardic, N.P. Malomuzh, and V.M. Sysoev, Functional form of the repulsive potential in the high pressure region, J. Mol. Phys. 120, 27 (2005) [DOI: 10.1016/j.molliq.2004.07.020].

19. V.Yu. Bardic, N.P. Malomuzh, K.S. Shakun, and V.M. Sysoev, Modification of an inverse-power potential for simple liquids and gases, J. Mol. Phys. 127, 96 (2006) [DOI: 10.1016/j.molliq.2006.03.026].

20. I.Z. Fisher, Ukr. Fiz. Zh. 20, 415 (1975).
21. L.D. Landau and E.M. Lifshitz, Statistical Physics, Part 1 (Pergamon Press, 1980).

22. J.O. Hirschfelder, C.F. Curtiss, R.B. Bird, The Molecular Theory of Gases and Liquids, (Wiley, New York, 1954) [ISBN-13 9780471400653].

23. N.P. Malomuzh, V.N. Makhlaichuk, P.V. Makhlaichuk et al., Cluster structure of water in accordance with the data on dielectric permittivity and heat capacity, J. Struct. Chem. 54, S205 (2013) [DOI: 10.1134/ S0022476613080039].

24. T. Ichiye and M.-L. Tan, Soft sticky dipole-quadrupoleoctupole potential energy function for liquid water: An approximate moment expansion, J. Chem. Phys. 124, 134504 (2006) [DOI: 10.1063/1.2161201].

Received 03.05.16.

Translated from Ukrainian by O.I. Voitenko

\section{M.B. Тимофеєе}

МОДЕЛЮВАННЯ ПОТЕНЦІАЛУ

ВЗАЄМОДІЇ МІЖ МОЛЕКУЛАМИ ВОДИ

$\mathrm{P}$ е $з$ ю м е

Досліджується структура і явний вигляд потенціалу міжмолекулярної взаємодії у водяній парі. Припускається, що основний внесок до нього вноситься силами відштовхування, дисперсійної та електростатичної взаємодії. Незвідна складова взаємодії, яка зумовлена перекриттям електронних оболонок і звичайно пов'язується з водневим зв'язком, вважається малою і відкидається. Побудовані потенціали, в яких: 1) відштовхування моделюється м'яким, степеневим, потенціалом, а електростатична взаємодія - відрізком мультипольного ряду до диполь-октупольної взаємодії включно і 2) відштовхування моделюється потенціалом твердих сфер, а електростатична взаємодія у той самий спосіб, що і в першому випадку. Дисперсійна взаємодія апроксимується стандартним чином в наближенні Лондона. Мультипольні моменти приймаються рівними їх експериментальним значенням, близьким до відповідних в квантово-хімічних розрахунках. Константи відштовхувальної і дисперсійної взаємодії підбираються так, щоб відтворити параметри ізольованого димеру і температурну залежність другого віріального коефіцієнта. Отримані таким чином вихідні потенціали використовуються для побудови усереднених потенціалів взаємодії, які визначають термодинамічні та кінетичні характеристики водяної пари. Характерною рисою потенціалу відштовхування молекул води є показник степеня $n=28$. Запропоновані потенціалі суттєво відрізняються від відомих потенціалів SPC, SPC/E, TIPS і т.п. 